Antropología Experimental

http://revistaselectronicas.ujaen.es/index.php/rae

2019. no 19 , Texto 27: 313-330

Universidad de Jaén (España)

ISSN: 1578-4282 Deposito legal: J-154-200

DOI: https://dx.doi.org/10.17561/rae.v19.27

Recibido: 31-07-2019 Admitido: 07-09-2019

\title{
NATURALEZA, CONSERVACIÓN E IDENTIDAD VERDE EN COSTA RICA ${ }^{1}$
}

\author{
Ángeles ARENAS; Beatriz PÉREZ GALÁN \\ UNED (España) \\ marenas136@alumno.uned.es, beatrizp@fsof.uned.es
}

\section{NATURE, CONSERVATION AND GREEN IDENTITY IN COSTA RICA}

\section{Resumen}

Costa Rica es uno de los destinos predilectos del turismo de naturaleza en América Latina y en el mundo. Este trabajo es una reflexión sobre el papel desempeñado por la conservación y la protección de áreas naturales -en especial de los Parques Naturales- en la representación del país, tanto en su proyección externa como en la conformación de su identidad nacional. El objetivo que se persigue es doble: por un lado, indagar sobre el peculiar proceso de patrimonialización de la naturaleza costarricense, sus usos institucionales, económicos y políticos, y su relación con una identidad nacional que diferencia a Costa Rica de otros países de la región al presentarse como una nación moderna, verde, de clase media, blanca, democrática y pacífica. Por otra parte, el artículo busca contribuir a la crítica sobre la deriva neoliberal experimentada por el modelo de conservación y desarrollo sostenible y su impacto en la mercantilización de la naturaleza.

\section{Abstract}

Costa Rica is one of the nature tourism favorite destination within America Latina and the world. The current article is a reflection on the importance of protected areas, especially national parks, in the country's representation both external and internal, where plays a role in the conformation of the national identity. The objective pursued by this text is twofold: on the one hand, to inquire about the peculiar process of patrimonialization of the Costa Rican natural environment, their institutional, economic and political uses, and their relationship with a national identity that differentiates Costa Rica from the rest of the region by presenting itself as a modern, green, middle class, white, democratic and peaceful nation. On the other hand, the article seeks to contribute to the criticism of the neo-liberal drift experienced by the conservation and sustainable development model and its impact on the commodification of nature.

\section{Palabras clave}

Naturaleza. Conservación Neoliberal. Parques Nacionales. Identidad. Turismo. Costa Rica Nature. Neoliberal Conservation. National Parks. Identity. Tourism

\footnotetext{
${ }^{1}$ Agradecemos a los profesores Francisco Sánchez, Gabriela Ossenbach, Beatriz Santamarina y Xenia Pacheco la lectura atenta de las versiones preliminares de este texto, así como sus atinadas propuestas de mejora.
} 


\section{Costa Rica, la "República Verde”}

"Hace más de 40 años adoptamos un amplio conjunto de políticas que propiciaran un desarrollo más armonioso con la naturaleza. Gracias a esas acciones hoy el $25 \%$ de nuestro territorio se encuentra bajo regímenes especiales de protección; contamos con una de las mayores coberturas boscosas del mundo equivalente a un $52 \%$ del territorio nacional; generamos más del $90 \%$ de la electricidad que consumimos de fuentes renovables; y somos uno de los cinco países más verdes del mundo. El compromiso con la sostenibilidad ambiental lo asumimos no solo como un deber ético, sino también como una exitosa estrategia de crecimiento y desarrollo. Contamos con una competitiva industria turística basada en el ecoturismo la cual triplica los recursos que aporta el llamado turismo de "sol y playa" y ayuda a financiar nuestro patrimonio natural. [...] Costa Rica es el tercer mayor exportador agrícola por unidad de territorio del mundo y algunos de nuestros productos de exportación agrícola como el banano o el café son certificados "carbono neutral". Extraemos valor de la bioprospección y de la investigación taxonómica de nuestros bosques con múltiples usos reales y potenciales en las industrias química y farmacéutica [...]" (L. Chinchilla Miranda, Río de Janeiro, 20 de junio de 2012).

Costa Rica es verde, para sí misma y para el mundo. Como se desprende del extracto del discurso pronunciado por la expresidenta de Costa Rica en la Conferencia de las Naciones Unidas sobre Desarrollo Sostenible (Río+20), la naturaleza adquiere una dimensión ontológica en la identidad nacional de este país. Se trata de un mensaje omnipresente que se reproduce y recrea en multitud de espacios de la vida cotidiana para propios y extraños: corona el escudo nacional con tres emblemáticos volcanes de la geografía costarricense; es un elemento indispensable en los libros de texto que leen los escolares; circula de mano en mano en el papel moneda que exhibe especies endémicas de la fauna costarricense; recibe o despide a los turistas a su llegada al aeropuerto en salas decoradas con enormes paneles que representan su exuberante naturaleza; guía el recorrido de la visita a la colección permanente del Museo Nacional, el más importante del país; y está presente como motivo de orgullo nacional en campañas electorales y publicitarias ${ }^{3}$. Los ejemplos son innumerables. La identidad verde y su imaginario asociado envuelven simbólicamente la esencia de Costa Rica y su proyecto de Estado-Nación moderno. Una "comunidad imaginada" (Anderson, 1993), construida social y políticamente a través de un discurso, unas prácticas y un conjunto de actores que se imaginan a sí mismos como miembros de ese grupo, de la que nos ocupamos en este texto.

Denominada la "green republic" (Evans, 1999) el mito de una nación verde, apuntalado también en las ideas de democracia y paz, resulta fundamental en la identidad nacional y su proyección global como icono del desarrollo sostenible. Costa Rica se ha convertido en un arquetipo de la identidad verde y un "ejemplo" de gestión ambiental y conservación ostentando el 14ํㅜ puesto a nivel mundial con mayor porcentaje de áreas protegidas que ocupan una cuarta parte del territorio (Boza, 2015, Corrales y Esquivel, 2017). Esta imagen contrasta sin embargo con las

\footnotetext{
2 Creado a fines del siglo XIX, el Museo Nacional de Costa Rica (San José), alberga colecciones de historia natural, arqueología e historia contemporánea del país. Este museo, uno de los más visitados del país, constituye una excelente metáfora en el espacio urbano público del proyecto de nación. Desde el propio emplazamiento que ocupa desde 1950 (un antiguo cuartel transformado en museo con la abolición del ejército), pasando por la propuesta museográfica (con claro énfasis en la historia natural), y el diseño del circuito para su visita (que comienza en un mariposario y culmina en una sala dedicada a los espacios protegidos en el país).

3 En el discurso de toma de posesión como presidente de la República (8 de mayo de 2018), Carlos Alvarado destacó cinco elementos que son motivo de orgullo para los costarricenses: "la ausencia de ejército, la paz, la democracia, el seguro social y un sistema de Parques Nacionales envidiable".
} 
deficiencias en la gestión ambiental que se reportan anualmente (PNUD, 2014; Alvarado y Aguilar, 2017; Corrales, 2012). Los informes destacan la elevada contaminación por agroquímicos y vertidos directos de alcantarillado de cuencas hidrográficas y acuíferos; el crecimiento descontrolado del sector turístico e inmobiliario con escasa o nula planificación; la sobreexplotación de los recursos marinos; la expansión de monocultivos de piña y banano de alto impacto ecológico, social y laboral; la extensión de la minería a cielo abierto; y la violación sistemática de los derechos territoriales de los pueblos indígenas permitiendo la usurpación de sus tierras por parte de colonos no indígenas que promueven la ganadería extensiva (Zuniga, 2018, Bozzoli, 2018; Slon, 2018). Un panorama que pone de relieve la falta de rumbo experimentada por el modelo de desarrollo sostenible y la paulatina "neoliberalización de la naturaleza" (Igoe y Brockington, 2007) relacionada con la política de conservación de espacios naturales de la que Costa Rica es un ejemplo paradigmático.

En este artículo entendemos la patrimonialización de la naturaleza como una construcción social y política que implica la identificación, selección y puesta en valor de determinados territorios frente a otros y su conversión en un recurso económico, tal y como es estudiado desde la antropología ambiental (Colding, 1997; Santamarina, 2006, 2009; West, Igoe y Brockington, 2006; Igoe y Brockington, 2007; Beltrán, Pascual y Vaccaro, 2008; Santamarina, Coca y Beltrán, 2018).

Al tratarse de un asunto eminentemente político-institucional, los procesos de patrimonializacion de la naturaleza requieren de ciertas condiciones previas. En primer lugar, asumir que entre naturaleza y cultura existe una separación ontológica -idea ampliamente debatida en antropología (Descola, 2012; West, Igoe y Brockington, 2006). En segundo lugar, entender esta relación de un modo paternalista donde la sociedad tiene la responsabilidad de ocuparse de la conservación y protección de la naturaleza -determinadas áreas- frente a los estragos causados por ella misma (Santamarina, 2009). Nos encontramos así frente a un bien colectivo que las autoridades deben preservar para generaciones futuras.

Igoe y Brockington (2007) analizan la trayectoria neoliberal de los procesos de conservación de la naturaleza y sus impactos. Para los autores, el paulatino desarrollo de políticas de conservación a escala global no se traduce en una desregulación de la naturaleza estricto senso sino más bien en nuevas formas de re-territorialización y re-regulación. Estas nuevas formas producen nuevos tipos de valor afines a los intereses de las élites nacionales y transnacionales mientras excluyen el control y la participación de la población local. Esta exclusión es criticada desde una perspectiva antropológica al considerar que la dimensión social y cultural de la patrimonialización de espacios naturales para su conservación fundamental y tan importante como la ecológica (Beltrán, Pascual y Vaccaro, 2008; Santamarina, Coca y Beltrán, 2018)

Para su concreción práctica en un proceso de "reverdecimiento" político económico e institucional, este modelo requiere de la emergencia de nuevas redes que aúnen los intereses del Estado, las empresas multinacionales, y las grandes Organizaciones No Gubernamentales (ONGs) impulsoras de la conservación y el turismo de naturaleza a nivel internacional.

De ese modo la naturaleza y, de modo más preciso, la biodiversidad, se convierten en un conjunto de bienes y servicios que se poseen y a los que se asigna un valor económico de mercado sometido a la ley de la oferta y la demanda. Los antecedentes de este modelo se remontan a nivel internacional al periodo comprendido entre la primera y la segunda Cumbre de la Tierra (19721992). En ese periodo, como estudia Santamarina (2006), el debate acerca de los límites del crecimiento y la desigualdad va poco a poco siendo sustituido por el del crecimiento sin límites del desarrollo sostenible que es convertido por las organizaciones internacionales y ciertos países en doctrina oficial (Informe Brundtland, 1987). A comienzos del siglo XXI ese modelo es complementado por el del llamado "capitalismo verde"4, cuyos impactos han sido ampliamente debatidos

\footnotetext{
4 "Ecocapitalismo", "capitalismo verde", son términos empleados indistintamente para referirse a una concepción del capitalismo en la que se incorporan los principios del ecologismo a los de la economía de mercado. Por un lado, se basa en una reducción del impacto medioambiental de las mercancías en sí y de los procesos de producción, a través del reciclaje o la mayor eficiencia energética y tecnológica. Por otro, se fundamenta en el mercado como la principal herramienta para conseguir estos objetivos ambientales asociándolos a la privatización y mercantilización de los recursos
} 
desde la ecología política y la antropología del desarrollo (Sutcliffe, 1995; Escobar, 1995 y 1999; Leff, 1998; Murillo, 2004; Gómez-Baggethun, 2012; Roca, 2012).

Basándose en un sistema hibrido de gobernanza ambiental global que combina la gestión pública del Estado y privada (empresas, ONGS y asociaciones locales) este modelo, que abordamos en Costa Rica, consigue restringir la lógica de la conservación de la naturaleza a la valoración y obtención de incentivos económicos mediante la generalización de conceptos como "servicios ambientales" y otros afines.

Los "servicios ambientales" son definidos de forma genérica como "aquellos beneficios o utilidades que la naturaleza proporciona a la humanidad en su conjunto o a una región tales como belleza escénica, protección de la biodiversidad y suelos, o captación y retención de agua en los ecosistemas, entre otros" (Gómez-Baggethun et al., 2010; Maris, 2012). El uso de este concepto ${ }^{5}$ y su expresión en políticas y acciones prácticas de conservación consiguen que la naturaleza -o más precisamente la biodiversidad- se conviertan en un recurso que se posee. Al radicar su importancia en las utilidades que genera al ser humano, la biodiversidad está potencialmente sujeta a derechos de propiedad, leyes, normas y políticas. Se trata de una estrategia que se presenta como un asunto eminentemente técnico -léase "despolitizado"- y por lo tanto capaz de conciliar y hacer coexistir posiciones políticas aparentemente antagónicas ("desarrollistas" versus "conservacionistas") en torno al valor económico-estratégico de la naturaleza (Pérez Galán, 2017: 4-5).

El caso de Costa Rica ilustra esta paradoja. Por una parte, con políticas conservacionistas que promocionan la extensión y conservación de extensas áreas boscosas y recompensan económicamente a través del pago por servicios ambientales a quienes mantienen bosques, nacientes de agua, cuencas y áreas costeras. Por otra parte, y de manera simultánea con políticas extractivistas que promueven la deforestación y colonización de tierras indígenas para la expansión de monocultivos - piña, palma africana, palmito- con un uso extensivo de agroquímicos que contaminan acuíferos, comprometen la sustentabilidad de los recursos marinos y el equilibrio costero al fomentar concesiones internacionales para pesca industrial de arrastre y la destrucción de manglares en pro de un crecimiento desordenado del desarrollo inmobiliario turístico. Un modelo que ilustra la compatibilidad de una retórica verde que aboga por la conservación, mientras impulsa de facto el crecimiento productivo a costa de la naturaleza.

La exitosa implantación del modelo de desarrollo sostenible en África y América Latina desde los años noventa hasta la actualidad convierte a algunos de sus países en inesperados "campeones de la conservación" a nivel mundial ${ }^{6}$. La obtención de nuevos recursos para conservación de la biodiversidad a través de las redes de cooperación internacional, la activación de vías de participación democrática más directas y de mayores oportunidades de negocio para la población local, previo desmantelamiento de las estructuras del Estado, son algunas de las promesas del nuevo credo de la conservación neoliberal implementadas en Costa Rica.

Partiendo de estas premisas, en este texto indagamos en la estrecha relación que existe entre las políticas nacionales de conservación, a través del establecimiento del sistema de Parques y áreas protegidas, y la consolidación de la imagen de país ambientalista que situamos como parte de un proyecto más amplio de reverdecimiento institucional, político, económico y simbólico. Para ello nos ocupamos en primer lugar de situar el proyecto conservacionista en la segunda mitad del siglo XX. Específicamente a partir de los años 70 coincidiendo con el inicio del reconocimiento institucional de espacios naturales y su conversión en Parques Naturales, Reservas, Corredores Biológicos, y otras figuras de conservación de la naturaleza.

En segundo lugar, nos preguntamos en qué consiste ese proceso de normalización de los espacios naturales, cuáles son los viejos y nuevos actores sociales implicados y qué redes

naturales, convirtiéndolos en "capital natural”. Para una crítica del concepto véase: Martínez Alier y Schüpmann, 1992, Gómez-Baggethun, 2012, y Roca, 2012, entre otros.

5 La propuesta de los "servicios ambientales" se remonta a finales de los años 70 cuando algunos autores comienzan a criticar la dependencia social y económica en relación a los bienes y las funciones de la naturaleza. Para una revisión histórica de este concepto véase Gómez-Baggethun (2011).

${ }^{6}$ Es el caso de Tanzania que cuenta con aproximadamente el 30\% de su territorio protegido, Belize, más del 50\%, Guatemala, 30\%, y Panamá y Costa Rica en torno al 25\% (Igoe y Brockington, 2007: 437). 
conforman a nivel nacional e internacional.

La tercera y última sección, nos detenemos en analizar el papel desempeñado por el turismo de naturaleza en el desarrollo de este modelo de conservación, y cómo contribuye al apuntalamiento tanto interior como exterior de la identidad nacional costarricense en la actualidad.

\section{La construcción de una identidad verde}

Costa Rica es un país de pequeñas dimensiones con una población total menor a los cinco millones de habitantes que resulta singular en el contexto regional por diferentes motivos. Es una de las cuatro naciones latinoamericanas con mayor porcentaje de clase media (PNUD, 2014) ostentando el noveno lugar en el Î́ndice de Desarrollo Humano en la región (PNUD, 2017). A diferencia de los países vecinos destaca por su estabilidad democrática, social y económica que le convierte en un país receptor de población de países vecinos con la tasa de emigración más baja de América Central. Finalmente destaca por su apuesta política pionera por la conservación de sus espacios naturales, que ocupan el 26,5\% de la superficie del país (Corrales y Esquivel, 2017), y por el turismo de naturaleza, una floreciente industria que atrae anualmente a casi tres millones de visitantes y representa en torno al 5.4\% del PNB (Villalobos, Galdeano y Tolón, 2009: 96-97).

La idea de una Costa Rica excepcional, ejemplar y diferenciada del resto de los países vecinos hunde sus raíces en la primera mitad del siglo XIX. Acuña (2002) considera este período como el momento de la invención del proyecto de Estado-Nación costarricense que será liderado por los sectores hegemónicos de la sociedad. Para el autor, que ha rastreado el proceso de formación de los principales atributos de la nación costarricense, su "mitología política" se fundamenta en estos años.

A diferencia de países como México, Guatemala y Perú que sitúan el meollo de su identidad nacional en el legado cultural y monumental indígena prehispánico, las élites costarricenses promueven una idea de país diferenciado del resto de Centroamérica. La nación es concebida como una sociedad pacífica e igualitaria, descendiente de europeos, con una tenencia de la tierra en la que predomina el minifundio agrícola y el campesinado y una economía orientada a la extracción forestal y a la producción cafetera y agroexportadora. Desde un punto de vista demográfico y cultural esta noción de pueblo homogéneo de criollos blancos y lengua castellana excluye tanto a la población antillana (negros y mulatos, y chinos en menor medida) que llegó al Caribe desde mediados del S. XIX con la construcción del ferrocarril, como a la población indígena de los 8 grupos étnicos que hoy representan en torno al $2 \%$ de la población 7 . Éstos quedan así relegados a la periferia simbólica y geográfica en la que radica la identidad nacional, es decir, fuera del Valle Central $^{8}$. Un siglo más tarde, la creación de Parques Naturales y otros espacios protegidos contribuirán decisivamente a consolidar esta idea.

A mediados del S. XX el país inicia un periodo de estabilidad democrática impulsado por un Estado intervencionista que promueve la sustitución de importaciones, la industrialización y la diversificación agrícola junto con medidas de bienestar social que favorecen un aumento paulatino de la clase media. En poco más de tres décadas se moderniza el país: se elimina el ejército, se nacionaliza la banca, se desarrolla una política pública social y educativa, y Costa Rica pasa a jugar un rol en la arena internacional al convertirse en uno de los 8 primeros países neutrales reconocidos por la ONU. Este modelo se mantiene hasta los años 80 cuando comienza a desmoronarse. La crisis latinoamericana de la deuda externa, impone una agenda neoliberal que se implanta en el país y en el resto del continente. Siguiendo las directrices del "Consenso de Washington" se impone un acelerado proceso de privatización, de adelgazamiento del sector público y de terciarización de la actividad económica. Para responder a esta situación Costa Rica apuesta por la

\footnotetext{
7 La población indígena de Costa Rica se compone de 8 grupos étnicos: bribris y cabécares, los grupos más numerosos, ngöbes, chorotegas, huetares, malekus, borucas y teribes. Estos grupos representan en torno al 2,3\% del país (X Censo de Población, 2010). De ellos, aproximadamente el 60\% vive en una de los 24 los territorios indígenas (reservas), ubicadas en la provincia de Limón, al norte, y Punta Arenas, en el Pacífico, y el 40\% restante en los cantones colindantes y en las grandes ciudades.

8 Es la región geográfica ubicada en el centro del país en la cual se ubican los núcleos urbanos más poblados y desarrollados del país (San José, Heredia Alhajuela y Cartago).
} 
retórica del desarrollo sostenible y alinea sus prioridades nacionales con la acción climática global y la conservación de la naturaleza. En palabras del entonces presidente y premio Nobel de la paz Oscar Arias: "Lo importante identificar los campos en los que puede competirse con ventaja en los mercados mundiales para promover la producción destinada a esos mercados [...]". La conservación de espacios naturales se convierte así en el nicho de oportunidad que permitirá al país lanzarse al mercado internacional y, en opinión de varios autores, en una eficaz "cortina de humo" que actúa para cubrir los cambios estructurales que acontecen bajo el beneplácito de los organismos internacionales (Hidalgo, 2000; Rojas, 2008; Cuevas y Mora, 2013; Isla, 2015).

Esta apuesta por el desarrollo sostenible se apoya en tres pilares interrelacionados: la patrimonialización de extensas áreas naturales, la actualización de su proyecto identitario nacional, y el impulso del turismo receptivo vinculado a actividades en la naturaleza.

\section{El reverdecimiento institucional. De tierras baldías a espacios protegidos}

Algunos autores distinguen dos momentos en las políticas de conservación en el país, situando una primera etapa entre el primer cuarto del siglo XIX hasta mediados del siglo XX (Chacón, 2003). Las acciones conservacionistas de este periodo responden a un particular modelo de relación con el entorno bajo los ideales positivistas de progreso y desarrollo cuya dimensión práctica se concreta en la transformación productiva de la naturaleza en terrenos fundamentalmente agrarios. Como recuerda Goebel (2006), estas primeras medidas ambientales se rigen por una orientación donde la utilidad se establece como valor motriz y la naturaleza como una fuente de materias primas para la sociedad. Bajo esta lógica, y durante algunas décadas más, la frontera agrícola avanzará promovida por un gobierno que premia con derechos de tenencia de la tierra la transformación del bosque en áreas de cultivo. De hecho, durante este periodo, el reconocimiento de derechos de propiedad sobre las tierras según las leyes -primero la "ley de baldíos nacionales" (1934) y posteriormente la "ley de informaciones posesorias" (1944)- exigía que éstas estuviesen desprovistas de cobertura forestal. Las metáforas utilizadas para referirse a estos procesos de transformación productiva del territorio son elocuentes: deforestar es "limpiar el monte", los terrenos "baldíos" u "ociosos" pasan a ser "útiles", "productivos" (Arenas, Mordt y Ríos, 2001).

La transformación de la propiedad de la tierra y de sus usos productivos provoca cambios profundos en el paisaje y también en la conformación económica, social e identitaria del país. La plantación de cafetales y posteriormente bananeras, palma y otros monocultivos tropicales, conlleva el desplazamiento de poblaciones indígenas y la creciente formación del campesinado. Paralelamente, la deforestación contribuye a desarrollar un próspero sector maderero exportador. Ello supone que, hasta el último tercio del siglo XX, el incipiente proceso de patrimonialización para la conservación de áreas naturales responde fundamentalmente a la necesidad de proteger fuentes de agua y asegurar el abastecimiento para poblaciones y cultivos, así como de preservar recursos forestales de alto valor económico para el Estado. De este modo, el conservacionismo temprano que lleva a declarar inalienables y bajo estricto control un conjunto de áreas del territorio en Costa Rica se caracteriza por una notable intervención del Estado en las políticas de colonización y explotación de la naturaleza para evitar el desaprovechamiento de recursos estratégicos con valor de mercado. Parafraseando a Goebel (2006: 39), el origen y desarrollo de los Parques Nacionales en Costa Rica se conforma como un complejo y dinámico proceso de concreción paulatina de medidas ecológicamente correctas con intenciones equivocadas.

En la década de los 40 y 50 el país comienza un acelerado proceso de modernización de la agricultura y la ganadería. La caficultura pasa de sombra a solana y la ganadería sustituye paulatinamente la especie bos taurus por la bos indicus, que requiere pastos no tolerantes a la sombra de los árboles. Estos cambios incrementan el proceso de deforestación que, sumado a la política de colonización de terrenos baldíos, produce fuertes variaciones en la cobertura forestal que pasa de ocupar el 90\% del territorio a finales del S. XIX al 75\% en 1940, 53\% en 1961, y 26\% en 1983. (Watson, 1998).

En ese contexto de intensa deforestación se prohíbe la extracción de roble y otras maderas y se establecen las primeras Reservas Forestales o Bosques Nacionales, dando así origen a los primeros Parques Nacionales. Mientras en 1961 se crea el Instituto de Tierras y Colonización, dos 
años más tarde se reconoce la primera área protegida bajo criterios de conservación promulgándose las primeras medidas para la conservación de las zonas circundantes a los cráteres de los volcanes y los ríos por parte del Instituto Costarricense de Turismo. No será hasta 1969 cuando estos decretos se vean refrendados con la primera Ley Forestal y la creación de la Dirección General Forestal y el Departamento de Parques Nacionales, más tarde Dirección de Parques Nacionales dependiente del Departamento Forestal del Ministerio de Agricultura. En 1994 ésta será sustituida por el Sistema Nacional de Áreas de Conservación (SINAC) dependiente del Ministerio de Ambiente.

La creación del SINAC, que integra la gestión de los servicios de vida silvestre, forestales y Parques Nacionales, supone un antes y un después en el proceso de reverdecimiento de Costa Rica. Ello se refleja en un virtual mapa donde el país completo se destina a la conservación-con el establecimiento de 11 áreas que en la actualidad albergan 172 áreas protegidas (166 territoriales y 6 marinas) de las cuales 28 son Parques Nacionales, Las áreas protegidas comprenden así un $26 \%$ de la superficie terrestre total y un $49 \%$ de sus aguas territoriales.

Cuadro. 1. Evolución histórica de las áreas protegidas en Costa Rica

\begin{tabular}{|c|c|}
\hline Año & Territorio Nacional en Áreas Protegidas \\
\hline 1955 & $0,5 \%$ \\
\hline 1973 & $0,7 \%$ \\
\hline 1978 & $2,6 \%$ \\
\hline 1980 & $4 \%$ \\
\hline 1984 & $8 \%$ \\
\hline 1987 & $10 \%$ \\
\hline 1988 & $11,23 \%$ \\
\hline 1991 & $12,5 \%$ \\
\hline 2000 & $24,6 \%$ \\
\hline 2016 & $25,4 \%$ \\
\hline & $26,55 \%$ \\
\hline
\end{tabular}

Fuente: Adaptado de Boza (2015).

Cuadro 2. Evolución del Sistema de Áreas Silvestres Protegidas de Costa Rica. 1955-2017

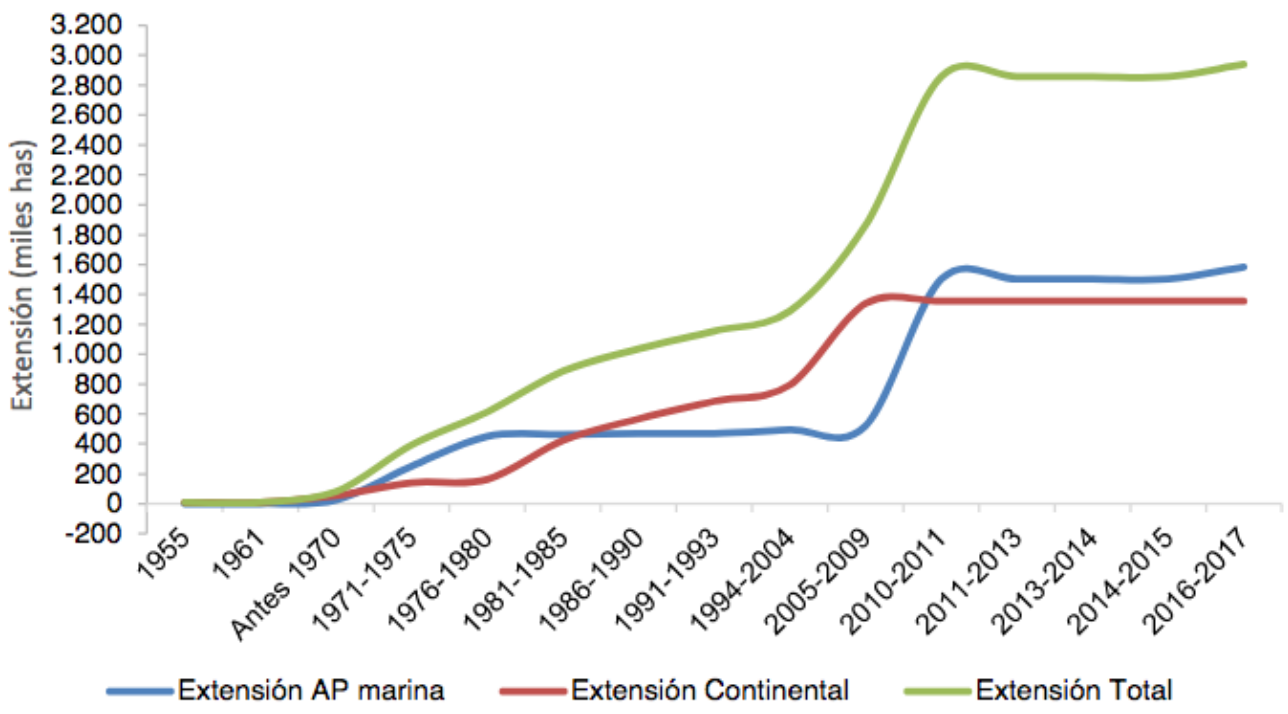

Fuente: Corrales y Esquivel (2017). 
El modelo de Parques Nacionales en Costa Rica está profundamente influido por el estadounidense. Ello se refleja conceptual y jurídicamente, en el estilo de gestión y en la proyección espacial que reproduce las ideas conservacionistas y de belleza escénica promovidas por el vecino del norte a través de la OEA (Organización de Estados Americanos). Es el Servicio de Parques Nacionales de Estados Unidos quien se encarga de la formación de los pioneros y promotores de las áreas protegidas en Costa Rica y, durante varias décadas, quien brinda servicios de asesoría, entrenamiento de personal, financiamiento e intercambio de expertos y voluntarios a través de los Cuerpos de Paz, de la AID y de la Fundación Costa Rica-USA.

Bajo este modelo conservacionista que coexiste con las políticas de colonización y transformación de terrenos baldíos, los Parques Nacionales quedan conformados como un conjunto de "manchas de bosque" aisladas y despobladas, a modo de islotes de vida silvestre circundados por áreas que han sufrido una fuerte modificación ambiental y demográfica. Al igual que en Estados Unidos, donde la patrimonialización permite una apropiación legal de territorios y recursos naturales ancestralmente utilizados por poblaciones autóctonas, la imagen de naturaleza prístina al margen de la cultura y de las poblaciones locales que rige la conservación en Costa Rica se "naturaliza" hasta tal punto que las áreas protegidas son tratadas como terra nullius ${ }^{9}$, esto es, espacios deshabitados simbólica y materialmente.

En varios países de América Latina como Bolivia, Ecuador, Perú, Colombia, Brasil, Nicaragua, Panamá y Venezuela, la cartografía de las áreas protegidas se solapa con la de los territorios indígenas lo que causa múltiples conflictos socioambientales por las restricciones en los usos del suelo y la creciente explotación de los recursos naturales por parte de empresas transnacionales (Cisneros y McBreen, 2010). En Costa Rica aparentemente no existiría esa competencia al no coincidir los límites demarcados por las áreas protegidas con los territorios indígenas establecidos por la "Ley indígena" en $1977^{10}$.

Sin embargo, una mirada más atenta a la cronología nos muestra que el proceso de demarcación y reconocimiento de los 24 territorios indígenas que posee el país actualmente transcurre entre 1977 hasta 2001, de manera paralela al del establecimiento del sistema de Parques Naturales y áreas protegidas. Si bien el establecimiento de Parques Nacionales en Costa Rica no implica, como en el caso de Estados Unidos, una expropiación de territorios indígenas ni su confinamiento en Reservas todo parece indicar que se consolidan de facto procesos que, iniciados por las políticas de colonización y apropiación de tierras baldías, han desplazado a los pueblos indígenas hacia zonas aisladas bajo intensos procesos de marginación social y ecológica. Autores como Slon y Moya (2018) nos recuerdan que los pueblos indígenas de Costa Rica arrastran esta situación de exclusión y desposesión simbólica y material de derechos territoriales hasta la actualidad.

Finalmente, en concordancia con las tendencias globales en lo que se ha denominado la segunda ola patrimonializadora de la modernidad (Santamarina, 2009), el modelo de Parque Natural a modo de islas inconexas y sin gente va siendo sustituido por una propuesta más articuladora que incluye las áreas de amortiguamiento y permite la realización ciertas actividades a la población. Así, bajo argumentos técnicos y ambientalistas se amplía la protección a nuevos espacios y se realiza especial énfasis en la vinculación entre las diferentes áreas a través de Corredores Biológicos que, en ocasiones, sobrepasan las fronteras nacionales ${ }^{11}$. De este modo las áreas de

\footnotetext{
9 Expresión latina que significa "tierra de nadie". En derecho privado el concepto se utilizó en la época colonial para privar a los ocupantes indígenas de sus derechos de propiedad permitiendo el reparto de la propiedad entre los colonos. Esta idea ha estado muy presente en la política pública costarricense tanto para promover políticas de colonización y deforestación como para el establecimiento de sus Parques Nacionales.

${ }^{10}$ La Ley indígena estipula que la población colona no indígena que tenga propiedades en los territorios indígenas deberá ser expropiada, reubicada e indemnizada por el gobierno. Sin embargo los colonos han seguido usurpando esos territorios y expulsando a los indígenas. El asesinato del líder bribri Sergio Rojas en Salitre (Buenos Aires) en marzo de 2019, pone de manifiesto el elevado nivel de conflicto territorial existente y el incumplimiento de la ley por parte del Estado costarricense (Zuniga et al., 2018).

11 Corredor Biológico se define como "un territorio cuyo fin es proporcionar conectividad entre paisajes, ecosistemas y hábitat para asegurar el mantenimiento de la biodiversidad y de los procesos ecológicos y evolutivos" (Reglamento a la Ley de la Biodiversidad, Artículo 3). Como otras figuras de conservación, estos corredores se proyectan como espacios de naturaleza prístina que es necesario preservar de las poblaciones locales. En el caso del Corredor Mesoamericano a
} 
conservación salen de sus pequeños reductos y se expanden a la totalidad del país donde se superponen al resto de las lógicas de ordenamiento del territorio, pero sin lograr revertir o modificar prácticas de deterioro medioambiental. La razón es sencilla: la nueva institucionalidad creada carece fuera de las áreas protegidas de competencias para realizar modificaciones en ámbitos económicos, productivos y de infraestructura que permitirían eliminar solapamientos y contradicciones con las normativas ambientales. Todo ello resulta en una fragmentación de políticas y medidas de intervención, multiplicándose así las figuras de protección, las administraciones y los actores encargados de la conservación de espacios naturales.

Este proceso de reverdecimiento geográfico, institucional y simbólico se enmarca en el contexto de valorización y rentabilización económica del patrimonio natural que, con la irrupción del discurso ambientalista global, instaura en el "deber ser" la nueva retórica del desarrollo sostenible y los instrumentos que facilitan su puesta en práctica (Pérez Galán, 2017: 5).

En un país que necesita reinventarse para responder a la crisis, la conservación deja de ser así un asunto de biólogos, ecologistas, mecenas políticos y conservacionistas extranjeros para convertirse en una cuestión de Estado consagrada por los organismos internacionales y compatible con el modelo neoliberal. Los cambios producidos en el tejido social y en la privatización paulatina de las áreas protegidas en Costa Rica, estudiados por Arenas (2017), dan cuenta de este proceso.

\section{Economía verde, privatización ambiental y nuevos actores sociales}

De la mano de la patrimonialización y conservación de espacios naturales, un enorme despliegue institucional y normativo encargado de la producción y formación de nuevos actores sociales se asienta en el escenario costarricense, estudiado entre otros por Vargas (2003). Por una parte, se requieren nuevos profesionales: gestores y administradores de áreas protegidas, guardaparques, agentes de viajes y guías ecoturísticos, expertos en ambiente y manejo de vida silvestre, biólogos, ecólogos, naturalistas, especialistas de otras profesiones como economistas ambientales, abogados ambientalistas, y hacedores de políticas ambientales. Todos ellos necesitan ser formados en teorías y conceptos de acuerdo al credo del desarrollo sostenible y la conservación y tener capacidad de reproducirlo como un objeto de estudio en el ámbito académico.

Para capacitar a esta pléyade de nuevos actores las instituciones académicas -públicas y privadas- se ponen manos a la obra en desarrollar una oferta de estudios acordes a las nuevas demandas. Entre las que tienen un mayor impacto destacamos en primer lugar al INCAE, una prestigiosa escuela de negocios vinculada con la Universidad de Harvard. Esta institución, encargada de la formación de cuadros medios y líderes políticos en América Latina desde hace más de 50 años, resultará clave en el desarrollo y puesta en marcha de las estrategias de mercadeo de la naturaleza en Costa Rica. No menos relevante es el papel ocupado por el Centro Agronómico Tropical de Investigación y Enseñanza (CATIE), en la formación de cuadros técnicos con sus cursos de vida silvestre y en la definición y desarrollo de planes de manejo de los primeros Parques Nacionales. Por su parte, las universidades públicas (Universidad de Costa Rica -UCR- y Universidad Nacional -UNA-), desarrollan una activa política de alianzas con centros privados, especialmente procedentes de Estados Unidos, como la Organización de Estudios Tropicales (OET) y posteriormente participan en la gestación y establecimiento del Instituto Nacional de Biodiversidad (INBio). También en estos años se crean multitud de institutos, centros educativos y universidades privadas con el soporte financiero de Estados Unidos que promocionan o reorientan su oferta académica hacia la gestión empresarial del medio ambiente ${ }^{12}$. Dentro del mapa de nuevos actores sociales vinculados con la construcción del modelo de desarrollo sostenible de Costa Rica, un lugar

su paso por Guatemala, Grandia (en Igoe y Brockington, 2007) analiza el desplazamiento forzado de la población local para instalar en sus territorios plantaciones de árboles que compensen las emisiones de carbono.

12 Es el caso de EARTH, una conocida universidad privada norteamericana creada en 1990 cuya oferta académica incluye diplomados, maestrías, pregrados y cursos cortos en agricultura sostenible, silvicultura tropical, energías renovables, carbono neutro, liderazgo ambiental, turismo rural y desarrollo comunitario. Y de la Universidad para la PAZ, creada en 1980 al amparo de la ONU para el estudio de los conflictos internacionales, la paz y el desarrollo. En las últimas décadas la UPAZ ha reorientado su oferta académica en línea con el modelo identitario costarricense: paz, desarrollo sostenible y medio ambiente (https://www.upeace.org/). 
de singular importancia es ocupado por los Organismos Internacionales de Desarrollo, los donantes bilaterales ${ }^{13}$ y las grandes ONGs dedicadas a la conservación de la biodiversidad que en 2016 ascendían a 82 (González, 2016; MINAE y SINAC, 2016), así como por un fuerte asociacionismo comunitario.

Las primeras ONGs que promueven la conservación de áreas naturales como el Centro Científico Tropical (CCT) y la Organización de Estudios Tropicales (OET), se establecen en el país en la década de los años 60 bajo una visión conservacionista buscando preservar áreas colindantes a los Parques Nacionales. A menudo se trata de iniciativas de naturalistas extranjeros que compran fincas para protegerlas de las comunidades y fundan estaciones biológicas financiadas con donaciones privadas y de organismos internacionales dedicados a la actividad científica y a la privatización de los espacios naturales. Es el caso de la conocida organización The Nature Conservancy $(\mathrm{TNC})^{14}$, que desempeñará un papel protagonista en la creación del sistema del sistema de Parques Nacionales en Costa Rica y de la Fundación de Parques Nacionales, diseñada una década más tarde como un canal financiero directo que agilice la gestión autónoma de recursos para los Parques. También se instalan en el país oficinas regionales de organismos de carácter internacional como la poderosa Unión Internacional para la Conservación de la Naturaleza (UICN).

En la misma época comienzan a proliferar a nivel nacional y local ONGs que establecen los pilares del movimiento ambientalista en el país y que resultarán claves en la movilización ciudadana ${ }^{15}$ para amortiguar el impacto de las políticas de ajuste estructural implementadas durante el gobierno de Arias y los siguientes. A partir de este momento se abre formalmente en Costa Rica un espacio para la participación de la sociedad civil en la conservación, en gran medida vía terciarización de servicios por transferencia de fondos. Ello produce una verdadera eclosión de ONGs ambientalistas en el país de diverso corte ideológico que son alentadas y financiadas por el propio gobierno y los organismos internacionales. Durante este periodo de efervescencia muchas de ellas ejercen como contrapartes locales de la cooperación internacional -tanto multilateral como bilateral-, y de otras grandes ONGs (Big ONGs) popularmente conocidas como "BINGOS" ambientalistas ${ }^{16}$. Se establece así un auténtico "Estado paralelo" de la conservación y venta de productos y servicios para el mercado verde caracterizado por la dispersión, el solapamiento y el debilitamiento de las competencias públicas en materia de conservación de una naturaleza previamente mercantilizada. Modelo que continua vigente hasta hoy.

\section{Bioprospección y venta de Servicios Ambientales}

Probablemente uno de los ámbitos prácticos en los que mejor se concreta la deriva neoliberal del desarrollo sostenible y la conservación de la naturaleza sea el de la explotación comercial de productos y servicios ambientales que brindan los ecosistemas. Por un lado, nos referimos a la concesión de licencias a empresas privadas para realizar biosprospección ${ }^{17}, \mathrm{y}$, por otro, a la venta de Servicios Ambientales (SA) y Servicios Ecosistémicos (SE). Estas prácticas, en las que Costa

\footnotetext{
13 Durante la crisis económica de los años 80 y el proceso paralelo de reverdecimiento buena parte de las 26 organizaciones de ayuda internacional en Costa Rica (como CIDA de Canadá, DANIDA de Finlandia, GTZ de Alemania, FIINIDA de Finlandia, NORAD de Dinamarca y ODA de Inglaterra), orientaron su cooperación hacia proyectos de conservación. 14 Fundada en 1951, el trabajo de TNC en América Latina comenzó en 1975 respaldando la creación del sistema de Parques Nacionales en Costa Rica. Actualmente cuenta con 35 oficinas y 250 empleados en la región y está presente en 16 países de Latinoamérica, siendo reconocida como uno de los organismos más influyentes para la conservación de la naturaleza en la región.

${ }^{15}$ Es el caso de la Asociación Anai y de la Asociación de Conservación de la Naturaleza (ASCONA). Esta última surge de un movimiento estudiantil en protesta por la explotación de bauxita y da origen a la mayoría de ecologistas y conservacionistas que fundan nuevas organizaciones.

${ }^{16}$ Nos referimos a INBio, FUNDECOR, ASIREA, CODEFORSA, AMBIO, CORCOVADO, FECON, DEDARENA, ANDAR, Fundación NEOTROPICA, MONTEVERDE, PRETOMA, IRIRIA, TSCHO, APREFLOFAS, ASVO, FUNDE COOPERACIÓN, a la Fundación Arias y a otras directamente ligadas con el origen y promoción de las áreas de conservación que tuvieron su propia ONG como Tortuguero, Gandoca-Manzanillo, Corcovado, y Bahía Ballena

17 Monsanto, la compañía multinacional de producción y venta de agroquímicos y bioquímicos y pionera y líder en producción de semillas transgénicas del mundo, fue la primera que utilizar el concepto «bioprospección» en 1991, tras firmar un convenio con los jardines botánicos de Missouri para la recolección de microorganismos del suelo y plantas (Joyce 1991, citado en Rodríguez, 2003: 136).
} 
Rica es pionera en América Latina y en el mundo, implican el acuerdo entre los actores del capitalismo verde tanto públicos como privados revisados hasta aquí, con las empresas que comercializan estos servicios.

Entre los hitos más relevantes en la privatización comercial de las áreas protegidas en Costa Rica, destaca el contrato firmado en 1993 entre el Instituto Nacional de Biodiversidad (INBio), entidad privada fundada con fondos públicos, y la transnacional farmaceútica Merck Sharpe and Dohme, Inc. (convenio INBio-Merck). Este contrato responde al modelo clásico de bioprospección cuyo fin "exclusivamente científico" es encontrar productos farmacéuticos o industriales para patentar y comercializar sin necesidad de participación de la población local. No obstante, las evaluaciones realizadas al Convenio INBio-Merck (Guevara, 2002 citada en Rodríguez, 2003: 145) reportan escasos resultados en cuanto a la obtención de medicamentos exitosos, pero si más de 20 patentes publicadas por la empresa por innovaciones obtenidas a partir de las muestras de la biodiversidad costarricense. Desde una perspectiva antropológica los efectos de la bioprospección se traducen además en la expropiación del conocimiento vernáculo y la aplicación de derechos de propiedad a semillas, plantas, animales, microrganismos, genes y conocimientos locales ancestrales, socavando la soberanía de los Estados y de los grupos que atesoran esos conocimientos. Se trata de una forma de "saqueo verde" o biopiratería que, con todas las garantías legales y en el marco de un discurso ambientalista de sostenibilidad y conservación de la biodiversidad, vulnera de facto los derechos colectivos de pueblos autóctonos a la propiedad intelectual de los recursos genéticos y sus conocimientos tradicionales (Toledo, 2006; Pérez Galán, 2017).

Otro lugar privilegiado en la privatización de las áreas protegidas es el que ocupa el pago por "Servicios Ambientales" 18 concepto que se generaliza en Costa Rica a partir los años 90 del siglo XX y que conlleva una retribución por los servicios ambientales producidos por el bosque (protección de cuencas hidrográficas, belleza escénica, fijación/secuestro de carbono, y conservación de la biodiversidad) o por "Servicios Ecosistémicos"19 (PSE). Uno de los primeros ámbitos donde se refleja esta medida es en el aumento de la cuota de entrada para extranjeros a los Parques Nacionales -que pasa de 1 a 15 dólares- en 1994. Apenas dos años más tarde (1996) el "Pago por Servicios Ambientales" (PSA), se extrapola al ámbito de los bosques tropicales a través de un programa pionero. Su objetivo es proporcionar incentivos a los propietarios de terrenos "baldíos" a cambio de su conservación y/o para su transformación en plantaciones forestales, a menudo de especies alóctonas de rápido crecimiento para la exportación ${ }^{20}$. Para Rojas y Aylward (2003) e Isla (2015), el PSA representaría la evolución de los antiguos subsidios a los empresarios del sector maderero financiado ahora mediante donaciones o gravámenes directos sobre algunos productos como el combustible o los ingresos por áreas protegidas.

Otras medidas fundamentales en el proceso de mercantilización de la naturaleza y la paralela expansión de las áreas protegidas en el país que basan la conservación en la creación de incentivos económicos son los canjes de "deuda por naturaleza" y la "venta de bonos ambientales", cuya gestión y beneficio es a menudo externalizada a manos de empresas privadas, estudiadas por Pauchard (2000). Según este autor, para el desarrollo de estas iniciativas es fundamental situar la posición geopolítica privilegiada que ocupa Costa Rica en Centroamérica y su liderazgo en materia de arreglos institucionales para la puesta en marcha de compromisos internacionales frente al

\footnotetext{
18 El origen se remonta a finales de los años 70 cuando algunos autores comienzan a criticar la dependencia social y económica en relación a los bienes y las funciones de la naturaleza. Para una revisión histórica del concepto véase Gómez-Baggethun, 2011.

${ }^{19}$ Los Servicios Ecosistémicos son aquellos beneficios que la gente obtiene de los ecosistemas y que se catalogan en directos e indirectos. Serían beneficios directos los de aprovisionamiento (producción de agua y alimentos) y los de regulación (de ciclos como las inundaciones, degradación de los suelos, desecación y salinización, pestes y enfermedades). Los beneficios indirectos son los servicios de apoyo que permiten el buen funcionamiento del ecosistema que genera los servicios directos (como la fotosíntesis, la formación y almacenamiento de materia orgánica, el ciclo de nutrientes, la creación y asimilación del suelo y la neutralización de desechos tóxicos). También se consideran los beneficios no materiales de los ecosistemas como los servicios de recreación, estéticos y espirituales (servicios culturales). ${ }^{20}$ Como la teca y la melina, maderas tropicales que generan un impacto ambiental por la pérdida de biodiversidad y el agotamiento de los suelos.
} 
Cambio Climático como el Programa de Aplicación Conjunta ${ }^{21}$ y la creación de la Oficina Costarricense de Implementación Conjunta en 1994 -responsable de las negociaciones de cambio climático y contraparte gubernamental de posibles proyectos-. Bajo este paraguas institucional se desarrollan numerosos proyectos de mitigación de cambio climático en los campos de energía y usos del suelo que convierten a Costa Rica en el primer país de América Latina receptor neto de fondos de países desarrollados en aplicación de este tipo de programas ambientales y en el primer exportador de servicios ambientales a nivel mundial. Un ejemplo de "buenas prácticas" elogiado por organismos internacionales (PNUMA, PNUD, Banco Mundial), y cuestionado por organizaciones ecologistas críticas por considerarlo como un proceso de mercantilización de la biodiversidad, expropiación del conocimiento vernáculo y de los derechos a la propiedad intelectual y al territorio de las poblaciones locales (Rojas, 2008: 21-38; Rodríguez, 2003; Rojas y Aylward, 2003).

En la actualidad, si bien Costa Rica sigue siendo líder el mercado verde, el auge de alguna de las líneas más innovadoras como la bioprospección a través del INBio -actualmente cerrado- y la venta de bonos de carbono han decaído considerablemente. La crisis financiera global se tradujo en una disminución en la cooperación internacional y con ella también la "efervescencia ambiental" en el país. Desde entonces la mayoría de los organismos multilaterales y bilaterales de cooperación y ayuda financiera, cuyas sedes regionales Costa Rica albergaba en las décadas anteriores, fueron trasladados a Panamá.

No podemos terminar esta aproximación al intenso y meteórico proceso de reverdecimiento de la identidad nacional que por medio de la patrimonialización y conservación de la biodiversidad ha experimentado la nación sin hablar del turismo de naturaleza y la intensa labor desarrollada por el Instituto Costarricense de Turismo (ICT) en la construcción de la imagen país.

\section{Turismo verde, Parques Nacionales e identidad}

Al igual que en otros países de la región como México, Guatemala, Brasil o Perú, en Costa Rica el turismo receptivo ha ido cobrando una importancia creciente en la economía nacional, hasta convertirse al inicio de la década de los 90 en la primera fuente de divisas sobrepasando al café y al banano (Rojas y Aylward, 2003: 4). Según datos del ICT en 2017 las llegadas internacionales al país alcanzaron los 3 millones de personas, lo que supone groso modo un crecimiento exponencial sostenido desde fines de los años 90 hasta el momento actual de casi un millón de visitantes por cada 10 años hasta alcanzar los 3 millones en 2017. El destino principal del turismo que visita Costa Rica son sus playas y de forma creciente sus Parques Nacionales y áreas protegidas.

El establecimiento del ICT en 1955 marca un hito en las políticas públicas de conservación y en el desarrollo de los Parques Nacionales como recurso turístico. El binomio "turismo-Parque Nacional" emula el modelo ideológico e institucional estadounidense. El establecimiento de los primeros Parques Nacionales en Costa Rica busca reforzar la identidad nacional siguiendo criterios de "belleza escénica" (P.N. Volcán Poás), de "valor histórico" (P.N. Santa Rosa) y de "importancia crítica para la conservación de especies endémicas", caso de los arrecifes coralinos (P.N. Cahuita) y la tortuga verde (P.N. Tortuguero), en áreas ecológica y geográficamente diversas (Boza, 1993). La gestión de los Parques, al igual que en Estados Unidos, sigue un modelo segmentado en el que diferentes departamentos institucionales (vida silvestre, forestal, Parques Nacionales) se encargan de gestionar una naturaleza previamente patrimonializada, compartimentada, despojada de habitantes y convertida en un "Parque musealizado", con senderos y vías de entrada y salida bajo la protección de guardaparques. Un modelo que según Saari (2015, citado en Goebel, 2016: 77), persigue difundir un ideal de naturaleza capaz de generar una identidad nacional al tiempo que satisfacer las cambiantes demandas del turismo en tanto que sector estratégico en la economía nacional.

En este punto es preciso recordar que, si bien el turismo receptivo es el que genera el mayor

\footnotetext{
21 Programa previsto en el Protocolo de Kyoto que permite a los países industrializados cumplir parte de sus obligaciones de recortar las emisiones de gases de efecto invernadero pagando proyectos que reduzcan las emisiones en otros países.
} 
volumen de ingresos en el país, Costa Rica posee una amplia clase media que emplea parte de su ocio en visitar sus Parques Nacionales y otros espacios protegidos ${ }^{22}$ (Vargas, 2009; Osorio et al., 2017).

\section{Cuadro 3. Visitas al Sistema Nacional de Áreas Silvestres Protegidas (1990-2005)}

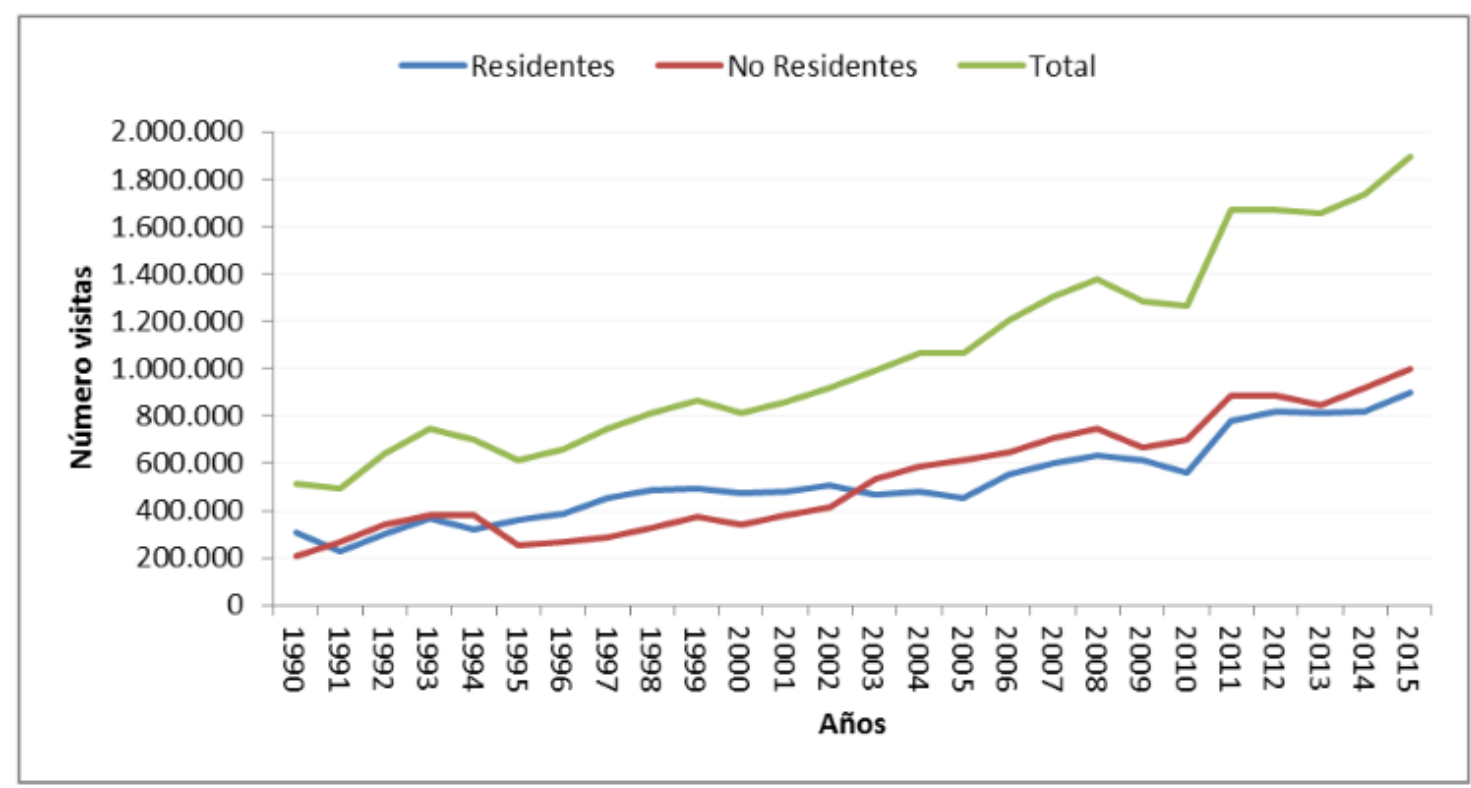

Fuente: Corrales (2016: 21).

Las estadísticas sobre visitas de turismo interno a los Parques Nacionales, que en algunos momentos del año superan a las del turismo receptivo, reflejan como los Parques se han convertido en otro de los rasgos de identidad colectiva apropiados por la población. Algunos de estos espacios, como el caso del P.N. "Volcán Poás", uno de los más visitados del país estudiado por A. Arenas (2017), continúa siendo un referente cultural intensamente antropizado y vivido por los costarricenses. Se trata de un espacio caleidoscópico construido socialmente a través de los usos, prácticas y visiones de mundo de los distintos grupos que convergen en él. A través de ellos el volcán se convierte en un espacio de espiritualidad y peregrinaje, de ocio, de ciencia, de visita turística, de disfrute dominical, o de interacción social.

Sirva una aproximación a la retórica de la promoción turística resulta relevante para completar esta reflexión sobre la reinvención del proyecto nacional de Costa Rica y su relación con la conservación de espacios naturales en el último medio siglo. Este "nosotros" que conforma la identidad nacional se proyecta a través de las campañas de marca país hacia afuera, esto es, dirigida al turismo receptivo, los inversores, los mercados globales, las ONGs y la corporación financiera internacional, entre otros. De manera simultánea también se proyecta hacia adentro, el tico ${ }^{23}$ es imaginado como "Pura Vida" y Costa Rica como un país moderno, competitivo, pacífico, democrático, de clases medias blancas y amante de la naturaleza (Bourkhis, 2012).

\section{Las narrativas turísticas. De Proyecto Nación a Marca País}

Las transformaciones que se producen a nivel global en los años 90 en el marco de un discurso global que promueve la sostenibilidad ambiental y cultural, se traducen también en nuevas

\footnotetext{
22 Según datos del ICT en el periodo de 2013-2017 tanto en el caso del turismo receptivo como en el turismo interno, las actividades relacionadas con la naturaleza como observación de la flora y la fauna, visita a los volcanes, caminatas por senderos, puentes colgantes, paseos en bote y avistamiento de aves, son las más desarrolladas (https://www.ict.go.cr/es/documentos-institucionales/estad\%C3\%ADsticas/cifras-tur\%C3\%ADsticas/actividadesrealizadas/1115-2013-2017/file.html [accedido el 18 de agosto de 2018]

23 Gentilicio coloquial: "costarricense".
} 
formas de viajar con una renovación de la oferta de turismo a nivel internacional. Aparecen así nuevos segmentos como el turismo sostenible, el turismo de naturaleza, el ecoturismo y el turismo rural cuya novedad principal respecto a otros tradicionales radica en que se trata de turismos de pequeño formato, menos gregarios y masificados, que buscan atraer la experiencia del turista en relación al patrimonio cultural y natural de cada región apostando por la preservación cultural y medioambiental de los lugares visitados como forma de agregar valor añadido a la actividad (Pérez Galán, 2012). Costa Rica, con su apuesta pionera por la conservación y el medio ambiente, logra un buen posicionamiento en el mercado a través de campañas promovidas por el ICT para atraer a esos nuevos viajeros.

Sin duda, una de las primeras campañas promocionales "Costa Rica: Sin Ingredientes Artificiales" 24 resultó muy exitosa en el empeño de reverdecer la imagen del país. Haciendo uso de lemas como el "Pura Vida" 25 se evoca la idea de naturaleza prístina, auténtica, exótica, materializada en la extensa red de Parques Nacionales y espacios protegidos. Al estar "no contaminados" por la mano del ser humano el turista puede experimentar una vuelta a lo natural versus "lo artificial" ("lo cultural"). Se presenta así un paraíso natural despoblado, como se deduce de los videos e imágenes promocionales en las que apenas aparecen personas y cuando excepcionalmente lo hacen, están en segundo plano practicando actividades y deportes en la naturaleza. El público al que se dirige esta marca es principalmente el turismo receptivo que proviene de Estados Unidos, Canadá y Europa para disfrutar de unas vacaciones visitando un destino exótico pero seguro con una gran biodiversidad, naturaleza exuberante, volcanes y hermosas playas rodeadas de vegetación. La campaña se ha mantenido vigente por casi dos décadas llevando a Costa Rica entre el 2009 y 2011 a ser reconocida en los rankings turísticos como la marca país más importante de América Latina (FutureBrand, 2012a, citado en Observatorio de Marca e Imagen de País, 2014).

Sin embargo, la oferta de turismo de naturaleza en sus múltiples variantes (ecoturismo, surf, rafting, canotaje, avistamiento de aves, canopy, trekking, volcanes, buceo), en la que Costa Rica goza de un lugar pionero e inmejorable en todo el mundo, comienza a crecer en otros países del continente como México, Panamá, Guatemala, Perú, Argentina y Chile que comparten paisajes de gran belleza escénica. Aunque el país sigue estando considerado como uno de los principales destinos de turismo de naturaleza del mundo, la competencia se intensifica y resulta necesario renovar y reforzar las ventajas comparativas que ofrece más allá de los atractivos naturales con los que cuenta. Por ello, la siguiente campaña mantiene la apuesta por la sostenibilidad ambiental y la integra en un proyecto de Nación pacífica, democrática y tecnologizada, con una población mayoritariamente blanca, de clase media, sonriente, profesional y confiable.

De este modo, la campaña "Costa Rica Esencial”, lanzada en 2013, actualiza con elementos de la modernidad neoliberal las señas de identidad nacional equilibrando la balanza naturalezasociedad:

“¿Quién soy? Soy la concentración atractiva de belleza, bosques, playas y biodiversidad...Vivo en el corazón de América, me custodian dos mares. Soy el verde profundo, y soy mucho más [...]. Soy una nación gobernada en paz, con una democracia antigua y consolidada, defiendo la salud, la educación y la superación de hombres y mujeres como pilares de la felicidad. En mi esencia están la preservación y el cuidado del medio ambiente, un ejemplo para el mundo [...]. Soy una nación confiable, creíble, diferenciada por el valor de lo que hago. Me distinguen el desarrollo humano, la innovación y una comprobada competitividad internacional que me permiten exportarle calidad al mundo [...]. Soy verde, soy felicidad, soy solidaridad, soy paz, soy talento, soy innovación, soy calidad, soy

\footnotetext{
24 Véase: https://paismarca.com/2014/09/29/el-origen-del-liderazgo-de-la-marca-pais-de-costa-rica/ [accedido el 18 de julio de 2018]

25 "Pura vida" es una frase usada cotidianamente en Costa Rica en situaciones variadas pero especialmente como respuesta a un saludo.
} 
diversidad, soy: Esencial Costa Rica" (video promocional campaña "Costa Rica Esencial"26).

Esta campaña consagra al fin, tras casi medio siglo de apuesta ideológica, política y económica, un "nosotros verde" parcialmente desexotizado. Sin renunciar al turismo de naturaleza al que se dirige a través del reclamo de animales exóticos y paisajes exuberantes incluye por primera vez al capital humano y la tecnología para inversionistas extranjeros interesados en productos y servicios ecológicos, agricultura orgánica, bioprospección, canjes de deuda por naturaleza y servicios ambientales. El disfrute de la naturaleza se complementa también con el turismo médico y el residencial dirigido a visitantes estadounidenses cuyo seguro médico es válido en Costa Rica y a pensionistas que pueden encontrar en el país en lugar donde pasar sus últimos años. La naturaleza sirve aquí como telón de fondo para un país que cuenta con sólidas instituciones democráticas, con una sociedad competitiva e innovadora, con una población talentosa, bien preparada, amable y receptiva y con un nivel de desarrollo y bienestar similar al de los países del "Primer Mundo".

\section{La apuesta por la naturaleza. Retórica y práctica}

En este texto hemos abordado el proceso de construcción de la identidad verde en Costa Rica y algunos de sus efectos. Hemos destacado cómo la patrimonialización de espacios naturales ha permitido que imaginar y reinventar una nación, en apenas cinco décadas. Desde una perspectiva antropológica se ha argumentado que la apuesta por la conservación de la naturaleza que realiza el Estado costarricense está embebida de razones económicas y político-ideológicas. Sus riquezas naturales cobran una nueva significación al ser patrimonializadas y ensalzadas de manera que sitúan al país muy cerca del internacionalmente valorado ideal de desarrollo sostenible y la conservación. Ello proporciona argumentos para una revalorización identitaria que produce un efecto amortiguador en la población ante el resquebrajamiento del modelo de Estado Nación de garantías sociales estable desde 1948.

Bajo encomiables razones de respeto a la naturaleza, a la biodiversidad, de compromiso con el planeta y con las generaciones futuras, los sucesivos gobiernos de Costa Rica, se ponen manos a la obra y, en línea con la retórica global del desarrollo sostenible, ratifican acuerdos y desarrollan políticas y marcos legales mediante los cuales la protección de la naturaleza adquiere definitivamente un valor económico y político per se. Este despliegue normativo sitúa a Costa Rica como un "alumno aventajado de la sosteniblidad", al menos en aquellos aspectos que no conllevan cambios estructurales de mayor calado político. También permite una buena proyección internacional a corto plazo y proporciona el marco necesario para el desarrollo de alianzas público-privadas con entidades conservacionistas de referencia internacional y con ONGs nacionales. Como parte del proceso, el Estado se reduce, con la fusión de parte de sus instituciones y la privatización y terciarización de muchas de sus responsabilidades. De un Estado proteccionista e interventor se transita a otro que debe apegarse al laissez-faire y reorientar una economía tradicionalmente productora de materias primas a otra cuyo peso recae en los bienes y servicios vinculados a la mercantilización de la naturaleza. Todo ello propicia un crecimiento del sector privado y una proliferación de nuevos actores en áreas como educación, salud, medio ambiente, generación energética, turismo, y otras. De este modo surge un verdadero Estado paralelo dedicado a la promoción y gestión de la llamada "economía verde", gracias a la cual la biodiversidad pasa de ser un obstáculo a convertirse en una oportunidad de negocio. Una fórmula que enfatiza la importancia de los mecanismos de mercado como garantía de preservación y diluye el conflicto clásico entre crecimiento y límites físicos, entre ecología y economía. La naturaleza queda convertida en medio de producción de bienes y servicios y, como tal, concebida y gestionada como una forma más de capital -el capital natural-, cuyo valor reside de modo casi exclusivo en el mercado.

Este modelo de desarrollo basado en la conservación adoptado de forma pionera en América Latina por Costa Rica permite su exitosa incursión en el mercado verde con nuevos productos 
como los canjes de deuda por naturaleza, la producción de energía limpia, los pagos por servicios ambientales y ecosistémicos, y los convenios y contratos firmados con grandes empresas farmacéuticas y biotecnológicas para realizar bioprospección. También posibilita que el país se sitúe entre los primeros de la lista internacional en la ratificación de los compromisos ambientales emanados de la Cumbre de la Tierra, hasta convertirse en uno de los países más beneficiados en la captación de fondos de la cooperación internacional destinados al medio ambiente y la conservación de la naturaleza. Situación también favorecida por su posición geoestratégica y por tratarse de un país de renta media que ofrece condiciones de seguridad para la inversión extranjera.

Finalmente, el modelo de desarrollo sostenible abre la puerta para que el turismo, en especial las nuevas variantes de turismo de naturaleza, se convierta en una de las principales fuentes de generación de ingresos del país y en una seña identitario. Esto último gracias a su incorporación a través de planes, programas y campañas de mercadeo de la marca país, a la retórica que fundamenta las bases políticas de la moderna identidad nacional. Nos encontramos así con un país democrático, pacífico y de clase media que se actualiza al incorporar como elemento identitario una biodiversidad celosamente guardada por el Estado a través de sus políticas conservacionistas y un sistema "ejemplar" de áreas protegidas. Parafraseando a Isla (2015: 22), se trata del primer "experimento verde" del neoliberalismo en América Latina que consigue hacer de la mercantilización de la naturaleza uno de los fundamentos de su identidad nacional.

\section{Bibliografía}

Acuña, V.H. (2002). "La invención de la diferencia costarricense, 1810-1870". Revista Historia no 45: 191228.

Alvarado, I., Aguilar, J (2017). La contabilidad del capital natural en Costa Rica. 23 informe del estado de la nación (pp. 179-232). San José: Programa del Estado de la Nación, San José, Costa Rica.

Anderson, B. (1993). Comunidades imaginadas. Reflexiones sobre el origen y difusión del nacionalismo, México: Fondo de Cultura Económica.

Arenas, A., Mordt, M., y Ríos, F. (2001). Territorio distante: El encuentro entre la gente y la naturaleza. Heredia: Universidad Nacional de Costa Rica.

Arenas, A. (2017). "Entramados significativos en el Parque Nacional Volcán Poás de Costa Rica” En: Vicente, T., M.J. García y T. Vizcaíno (eds.) Actas del XIV Congreso de Antropología: antropologías en transformación. Sentidos, compromisos y utopías. Valencia: Universitat de Valencia, pp. 1408-1424.

Beltrán, O., Pascual, J., y Vaccaro, I. (2008). Introducción. Espacios naturales protegidos, política y cultura. En Patrimonialización de la naturaleza. el marco social de las políticas ambientales. XI congreso de antropología de la FAAEE (pp. 11-25). Donostia: Ankulegi.

Borge C., y Esquivel, S. (2015). ONGs para la conservación de la biodiversidad. San José: Sistema Nacional de Áreas de Conservación.

Boukhris, L. (2012). El imaginario turístico a prueba de Costa Rica: Entre «ver» y «hacer» el territorio. Revista Internacional Interdisciplinar de Turismo.

Boza, M. A. (2015). Historia de la conservación de la naturaleza en Costa Rica 1754-2012. Cartago, Costa Rica: Editorial Tecnológica de Costa Rica.

Bozzoli, M.E. et al. (2018). Comisión Especial de Salitre. Informe Final. San José: Universidad de Costa Rica.

Carballo, J. (2014). "Políticas ambientales sostenibles en Costa Rica" Aguilero.Com, Información para la sustentabilidad y el cambio social.

Chacón, M. (2003). Historia y políticas nacionales de conservación. San José: Universidad Estatal de Educación a Distancia.

Cisneros, P., y McBreen, J. (2010). Superposición de territorios y áreas protegidas en América del sur (informe final). Ecuador: Unión Internacional para la Conservación de la Naturaleza.

Colding, J. (1997). Nature and society: Anthropological perspectives. Amsterdam: Elsevier Science Bv.

Corrales, L. (2012). Gestión del patrimonio, conservación y biodiversidad: Resultados de la gestión ambiental. Informe elaborado para el Decimoctavo informe del estado de la nación. San José: Programa del Estado de la Nación, San José, Costa Rica.

Corrales, L., y Esquivel, M. (2017). Cambio climático: Impactos y desafíos para Costa Rica. Informe elaborado para el Decimoséptimo informe estado de la nación en desarrollo humano sostenible. San José: Programa del Estado de la Nación en Desarrollo Humano Sostenible.

Cuevas, R., y Mora, A. (2013). Vendiendo las joyas de la abuela: Políticas culturales e identidad nacional en Costa Rica (1990-2010). San José: Universidad Estatal a Distancia de Costa Rica. 
Descola, P. (2012). Mas allá de naturaleza y cultura. Buenos Aires: Amorrortu.

Escobar, A. (1995). "El desarrollo sostenible. Diálogo de discursos". Ecología Política 9: 7-27.

Escobar, A. (1999). El final del salvaje: Naturaleza, cultura y política en la antropología contemporánea. Santa Fé de Bogotá: CEREC/ICAN.

Evans, S. (1999). The green republic: A conservation history of Costa Rica. Texas: University of Texas Press.

Goebel, A. (2006). Ciencia, legislación y discurso conservacionista. El " germen" de los parques nacionales en Costa Rica: Elementos contextuales y "matices" analíticos 1833-1955. Diálogos: Revista Electrónica de Historia, 6 (2), 1-39.

Goebel, A. (2016). Posibilidades de confluencia entre la(s) historia(s) ambiental(es) y los estudios cts. Las áreas de conservación como ejemplo analítico. Revista de Ciencias Sociales, III (153), 69-86.

Gómez-Baggethun E. (2011). "Análisis crítico de los Pagos por Servicios Ambientales: de la gestación teórica a la implementación”, Revista Española de Estudios Agrosociales y Pesqueros 228: 11-47.

Gómez-Baggethun E. (2012). "Economía verde o la mistificación del conflicto entre crecimiento y limites ecológicos”. Ecología Política. Monográfico Economía Verde. no 44.

González, L.A. (2016). El estado de la cooperación internacional en Costa Rica. Informe elaborado para el Vigesimosegundo informe estado de la nación en desarrollo humano sostenible. San José: Programa del Estado de la Nación en Desarrollo Humano Sostenible.

Hidalgo, A. L. (2000). ¿Un nuevo modelo estructural centroamericano? El reformismo neoliberal en América Latina y el cambio estructural en Costa Rica. Revista de Economía Mundial (Magazine of World Economy (Ies), 2(2), 87-119.

Informe Brundlant (1988). Nuestro Futuro Común, Madrid: Alianza Editorial

Igoe, J. y Brockington,D., (2007). "Neoliberal Conservation. A brief introduction". Conservation and Society, Vol. 5. No 4: 432-449.

Isla, A. (2015). The"greening" of Costa Rica: Women, peasants, indigenous peoples, and the remaking of nature. Toronto: University of Toronto Press.

Leff, E. (1998). Ecología y capital. Racionalidad ambiental, democracia participativa y desarrollo sustentable. Madrid y Ciudad de México: Siglo XXI.

Maris, V. (2012) "De la naturaleza a los servicios ecosistémicos. Una mercantilización de la biodiversidad" Ecología Política. Monográfico "Economía Verde”. no 44.

Martínez Alier, J. y Schüpmann, K. (1992). La economía y la ecología. Madrid: Fondo de Cultura Económica.

MINAE, Ministerio de Ambiente y Energía (2016). Informe Anual de Estadísticas SEMEC 2016. SINAC en Números 2016. San José, Costa Rica, Sistema Nacional de Áreas de Conservación.

MINAE, Ministerio de Ambiente y Energía (2017). ONGs para la conservación de la biodiversidad en Costa Rica. San José: MINAE.

Murillo, D. (2004). Falacias del desarrollo sustentable: una crítica desde la metamorfosis conceptual. Economía, Sociedad y Territorio, vol. IV. (16): 635-656.

Observatorio de Marca e Imagen de País (2014). El origen del liderazgo de la marca país de Costa Rica, https://paismarca.com/2014/09/29/el-origen-del-liderazgo-de-la-marca-pais-de-costa-rica/, [accedido el 30 de agosto de 2018]

Osorio, M., Monge, L., Serrano, R., y Cortés, I. (2017). Perfil del visitante de naturaleza en Latinoamérica: Prácticas, motivaciones e imaginarios. Estudio comparativo entre México y Ecuador. PASOS. Revista De Turismo y Patrimonio Cultural, 15(3): 713-729.

Pauchard, A. (2000). La experiencia de Costa Rica en áreas protegidas. Ambiente y Desarrollo, Vol XVI (No 3), pp. 51- 60.

Pérez Galán, B. (2017). Desarrollo sostenible y usos del patrimonio agrícola en los Andes. En: P. Tomé (ed.) Reflexiones rayanas. Asociación de Antropología de Castilla y León / CSIC. Vol. II. pp. 3-32.

Pérez Galán, B. y H. Asensio, R. (2012). Introducción. En: R. H. Asensio y B. Pérez Galán (eds.) ¿El turismo es cosa de pobres? Patrimonio Cultural, Pueblos indígenas y nuevas formas de turismo en América Latina, Lima/Tenerife: IEP/PASOS. Revista de Turismo y Patrimonio Cultural. Colección PASOS edita, no 8. Serie TURISMO, no 4. pp. 1-15.

Programa de las Naciones Unidas para el Desarrollo, PNUD. (2014). La equidad en Costa Rica: Incidencia de la política social y la política Fiscal.

Programa de las Naciones Unidas para el Medio Ambiente, PNUMA (2011). Hacia una economía verde. Guía para el desarrollo sostenible y la erradicación de la pobreza. Síntesis para los encargados de la formulación de políticas.

Roca, J. (2012). "La economía verde: términos y contenidos". Ecología Política. Monográfico "Economía Verde". № 44 .

Rodríguez, S. (2003). El Contexto histórico de la bioprospección y el modelo INBIO-Merck. Contratos de 
bioprospección: entre las promesas y la realidad, Debates ambientales: El valor de la Diversidad, 25: 135- 147.

Rojas, I. (2008). Mercantilización de la biodiversidad: La actividad de bioprospección del INBio en Costa Rica. Economía y Sociedad., (33/34), 21-38.

Rojas, M., y Aylward, B. (2003). ¿Qué estamos aprendiendo de la experiencia con los mercados de servicios ambientales en Costa Rica?: Revisión y critica de la literatura. International Institute for Environment and Development. http: //pubs.iied.org/pdfs/9247SIIED.pdf [accedido el 12 de agosto de 2018].

Santamarina, B. (2006). Ecología y poder. el discurso medioambiental como mercancía. Madrid: Los Libros de la Catarata.

Santamarina, B. (2009). "De parques y naturalezas. enunciados, cimientos y dispositivos". Revista de Dialectología y Tradiciones Populares, 64(1), 297-324.

Santamarina, B. (2016). "La naturaleza de las naturalezas patrimonializadas. una aproximación a las formas hegemónicas de representar lo natural”. Arxiu d'Etnografia De Catalunya, (16), 153-177.

Santamarina, B., Coca, A., y Beltrán, O. (2018) Antropología Ambiental. Conocimientos y prácticas locales a las puertas del antropoceno, Barcelona: Icaria/Institut Català d'Antropologia.

Slon, J.A., Moya, C. (2018) "Pueblos indígenas y Estado costarricense: disputa de derechos y control territorial” Revista Rupturas 8(2): 169-192.

Sutcliffe, B. (1995) "Desarrollo frente a ecología”. Ecología Política, 9: 27-49.

Toledo, Víctor (2006). El Nuevo régimen internacional de derechos de propiedad intelectual y los derechos de los pueblos indígenas. En: M. Berraondo (ed.) Pueblos Indígenas y Derechos Humanos, Bilbao: Instituto de Derechos Humanos de Deusto- Alto Comisionado de Naciones Unidas Para los Derechos Humanos. ONU. pp- 5093-536.

Tomé, P. (2009). Miradas antropológicas a las relaciones entre naturaleza y cultura. A modo de introducción. Revista de Dialectología y Tradiciones Populares, 64(1), 7-22.

Vaccaro, I., Beltrán, O., y Paquet, A. (2012). Antropología de la conservación. Naturaleza, Estado, Mercado y Cultura. En B. Santamarina (ed.), Geopolíticas patrimoniales. de culturas, naturalezas e inmaterialidades. Una mirada etnográfica, Valencia: Germanias: 29-53.

Vargas, G. (2009). Turismo y espacios naturales protegidos en Costa Rica: Enfrentamiento o concertación. Revista de Ciencias Sociales, (123-124), 49-78.

Vargas, M. (2003). Historia y políticas nacionales de conservación, San José: Editorial Universidad de Educación a Distancia, EUNED.

Villalobos, D., Galdeano, E., y Tolón, A. (2009). Demanda turística internacional por turismo naturaleza en: Costa Rica: Indicadores socio-demográficos y de condición de viaje. Ciencias Económicas, 27(2), 75103.

Watson, V. (1998). Abriendo espacio para una mejor actividad forestal. Políticas exitosas para los bosques y la gente. San José: Junta Nacional Forestal Campesina / Centro Científico Tropical (CCT)/ International Institute for Environment and Development (IIED).

West, P. Igoe, J. y Brockington, D. (2006). "Parks and Peoples: The social impact of protected áreas". Annual Review of Anthropology, 35: 251-277.

Zuniga, X., et al. (2018). Informe final de investigación: El territorio de Salitre: derechos, memoria y violencia, 2010-2017. San José: Universidad Estatal a Distancia (UNED) / Centro de Investigación en Cultura y Desarrollo (CICDE). 